Review Article

\title{
Autophagy-Associated lncRNAs: Promising Targets for Neurological Disease Diagnosis and Therapy
}

\author{
Xiangming Xu, ${ }^{1,2}$ Lili Cui $\mathbb{D}^{1}{ }^{1}$ Wangtao Zhong $\mathbb{D}^{1,2}$ and Yujie Cai $\mathbb{D}^{1}$ \\ ${ }^{1}$ Guangdong Key Laboratory of Aged-Related Cardiac and Cerebral Diseases, Affiliated Hospital of Guangdong Medical University, \\ Zhanjiang, China \\ ${ }^{2}$ Department of Neurology, Affiliated Hospital of Guangdong Medical University, Zhanjiang, China
}

Correspondence should be addressed to Wangtao Zhong; 158980116@qq.com and Yujie Cai; musejie163@163.com

Received 15 July 2020; Revised 13 August 2020; Accepted 1 September 2020; Published 22 September 2020

Academic Editor: Zygmunt Galdzicki

Copyright (C) 2020 Xiangming Xu et al. This is an open access article distributed under the Creative Commons Attribution License, which permits unrestricted use, distribution, and reproduction in any medium, provided the original work is properly cited.

Neurological diseases are a major threat to global public health and prosperity. The number of patients with neurological diseases is increasing due to the population aging and increasing life expectancy. Autophagy is one of the crucial mechanisms to maintain nerve cellular homeostasis. Numerous studies have demonstrated that autophagy plays a dual role in neurological diseases. Long noncoding RNAs (lncRNAs) are a vital class of noncoding RNAs with a length of more than 200 nucleotides and cannot encode proteins themselves but are expressed in most neurological diseases. An early phase, emerging knowledge has revealed that long noncoding RNAs (lncRNAs) are crucial in autophagy regulation. Furthermore, autophagy-associated lncRNAs can promote the development of neurological diseases or slow their progression. In this review, we introduce a general overview of lncRNA functional mechanisms and summarizes the recent progress of lncRNAs on autophagy regulation in neurological diseases to reveal possible novel therapeutic targets or useful biomarkers.

\section{Introduction}

Neurological diseases are important causes of human disability and death worldwide. According to the pathology, they can be divided into several groups, including cerebrovasculardiseases, neurodegenerative diseases, demyelinating diseases, infectious diseases, brain tumors, epilepsy, and headache. Most neurological diseases occur after the developmental maturation of CNS [1]. Autophagy is an important catabolic process during which the unwanted cytoplasmic components such as damaged organelles and protein aggregates are sequestered and engulfed by double-membrane vesicles called autophagosomes, and then autophagosomes fuse with lysosomes to form autolysosomes where the cargos are degraded and recycled [2-4]. Autophagy can be divided into basal autophagy and induced autophagy [5]. Several studies have demonstrated that basal autophagy plays a housekeeping role in eukaryotes through degrading useless and dysfunctional proteins and organelles to maintain cellular homeostasis and promote cell growth and development [3, 6]. Compared with basal autophagy, the degree of induced autophagy is significantly increased, which is a defensive response of the body to external stimuli and may cause autophagic cell death [5]. Neuronal autophagy plays an essential role in synaptic plasticity, oligodendrocyte development, anti-inflammatory function in glial cells, and myelination process $[7,8]$. As postmitotic cells, nerve cells are unable to dispose toxic or misfolded proteins through cell division. Therefore, proper autophagy is crucial for nerve cells to remove harmful cellular components; however, insufficient activation of autophagy or pathological stress inducedautophagy will lead to the accumulation of those harmful constituents and eventually causes neuronal dysfunction, which is associated with neurological diseases such as Alzheimer's disease (AD), Parkinson's disease (PD), ischemic stroke (IS), and glioma [9].

Recently, noncoding RNA, such as long noncoding RNA (lncRNA), have been verified to regulate cell autophagy by several mechanisms and further contribute to many of the characteristics of disease phenotypes [10]: (1) lncRNA can sponge some miRNAs which directly target autophagyrelated proteins to regulate autophagy. For example, lncRNA 
APF regulates miR-188-3p, thereby affecting the expression of ATG7 which is an autophagy factor [11]. FLJ11812 can regulate the level of the miR-4459 target ATG13 (autophagy-related 13) and then promote autophagy [12]. Similarly, IncRNA TGFB2-OT1 has been found to regulate the expression of autophagy-related proteins CERS1, NAT8L, and LARP1 by binding to miR-3960, miR-4488, and miR-4459 [13]. (2) lncRNA can also target autophagy-related signaling pathways, such as lncRNA H19 and lncRNA HOTAIR. In this review, we will discuss not only the current knowledge about the relationship between autophagy and neurological diseases but also the possible biological functions of lncRNA in regulating autophagy and summarize some specific studies that have provided novel insights into the underlying mechanism of the lncRNA-autophagy axis for neurological disease pathogenesis and therapeutic intervention.

\section{IncRNA Characteristics, Classification, and Functional Mechanisms}

Long noncoding RNAs (lncRNAs) are a vital class of noncoding RNAs with a length of more than 200 nucleotides. Surprisingly, although lncRNAs cannot encode proteins themselves, they are known to be $5^{\prime}$ capped, $3^{\prime}$ polyadenylated, and spliced similar to mRNAs. According to their location in the genome relative to nearby protein-coding genes, lncRNAs are generally divided into major groups: sense lncRNAs, antisense lncRNAs, bidirectional lncRNAs, enhancer lncRNAs, intronic lncRNAs, and intergenic lncRNAs [14-16]. They are widespread in most eukaryotic transcriptome and constitute a significant fraction of mammalian genomes, which are involved in cell growth, proliferation, differentiation, apoptosis, metabolism, and other biological processes $[17,18]$. With the rapid development of high-throughput sequencing and gene chip technology, a large number of studies have indicated that lncRNA participates in the pathophysiology of various diseases, such as cancer, aging, cardiovascular and cerebrovascular diseases, and neurodegenerative disorders; however, its underlying molecular mechanism is still not well clarified [19-21]. The latest study showed that lncRNA functions generally by five modes of action: signals, decoys, sponges, guides, and scaffold [22, 23] (Figure 1). (1) In response to cell signaling or other stimuli from extracellular environments, lncRNAs that serve as signals will be transcribed and directly regulate the transcription of the downstream gene (Figure 1(a)). This process is directly regulated by lncRNA and does not involve protein translation, so it can respond to external stimuli quickly [24]. (2) lncRNAs can act as a decoy to bind to transcription factors or transcriptional regulating factors and then block its molecular action or other signaling components that regulate the transcription of downstream genes [23] (Figure 1(b)). (3) Interestingly, lncRNAs often function as competitive endogenous RNA (ceRNAs), namely, miRNA sponges or antagonists [25]. More specifically, IncRNAs can bind to miRNA with base pair sequence complementarity, which will repress the binding of miRNA to the $3^{\prime}$ untranslated regions (UTRs) of its target mRNA, protecting mRNA from degrading and consequently regulating protein translation [26, 27] (Figure 1(c)). (4) Besides, lncRNAs are also involved in posttranscriptional modification and alternative splicing of mRNA [28] (Figure 1(d)). (5) lncRNAs which serve as guide RNAs are classified into two categories cis-acting and transacting. These lncRNAs can combine with proteins such as transcription factors and transcriptional regulating factors and direct these RNA-protein complexes to the specific DNA sites, contributing to regulating transcription precisely [23] (Figure 1(e)).

(6) IncRNAs that act as a scaffold are like a central platform, and multiple relevant transcription factors can be bound to these lncRNAs to regulate the activity of transcription factors. Besides, multiple signaling pathways are activated or inhibited, and their downstream effector molecules can be bound to the platform to achieve information intersection and integration between different signaling pathways [29-31] (Figure 1(f)). It is worth noting that the abovementioned modes of action of lncRNA do not exist independently, but are interrelated and interact with each other. Numerous studies have revealed that lncRNAs are highly expressed in a mammalian brain tissue and play a significant role in regulating protein-coding gene expression through the epigenetic, transcriptional, and posttranscriptional levels and are involved in multiple signaling pathways of various neurological diseases, which has a very broad clinical application prospect [32-34].

\section{IncRNA as Regulators of Autophagy in Neurological Diseases}

Autophagy is one of the crucial mechanisms to maintain nerve cellular homeostasis; however, numerous researches have shown that autophagy is a double-edged sword that can either protect cells against apoptosis or promote autophagic cell death. The activation of autophagy has been documented in various diseases such as cancer, $\mathrm{AD}, \mathrm{PD}$, and vascular diseases $[35,36]$. Similar to other signaling pathways, autophagy is regulated by several factors, including transcription factors and noncoding RNAs such as lncRNAs and miRNAs. There is growing evidence that noncoding RNAs regulate diverse pathophysiological processes in vivo and in vitro, from cell proliferation to aging, are both closely associated with autophagy. Besides this, the deregulation of lncRNAs will contribute to numerous neurological diseases [37]. In this section, we will introduce some recent findings that shed light on the role of lncRNA-mediated autophagy in some common neurological diseases (Table 1).

3.1. IncRNA-Mediated Autophagy in Alzheimer's Disease. Alzheimer's disease (AD) is one of the most common agerelated neurodegenerative diseases and causes progressive memory impairment and cognitive dysfunction, accounting for $70 \%$ of cases of dementia [38]. However, the etiology and pathogenesis of $\mathrm{AD}$ remain unclear. At present, most scholars believe that the extracellular disposition of $\beta$-amyloid $(\mathrm{A} \beta)$ and the intraneuronal accumulation of tau protein are two major neuropathological features of AD. Studies have shown that autophagy inducers seem to prevent the 

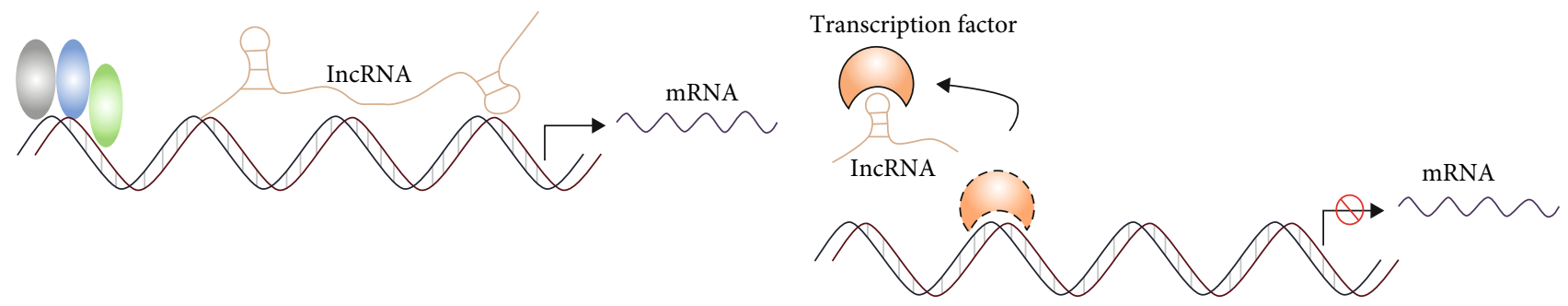

(a)

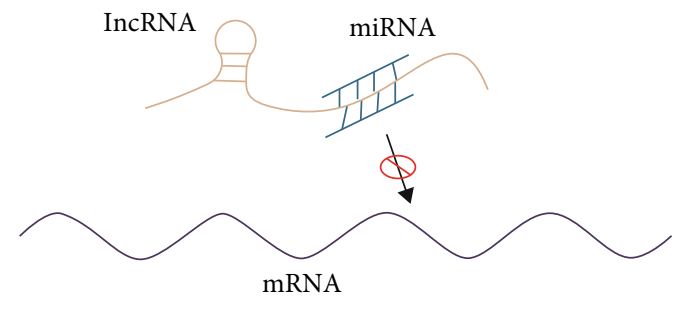

(c)

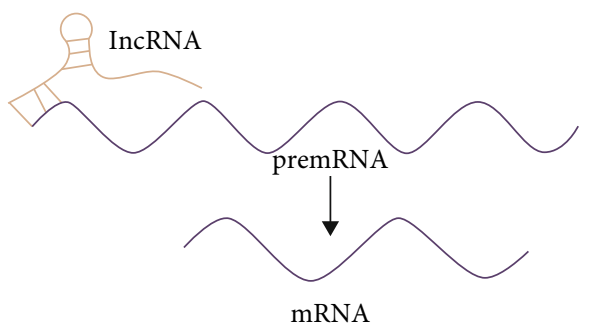

(d)

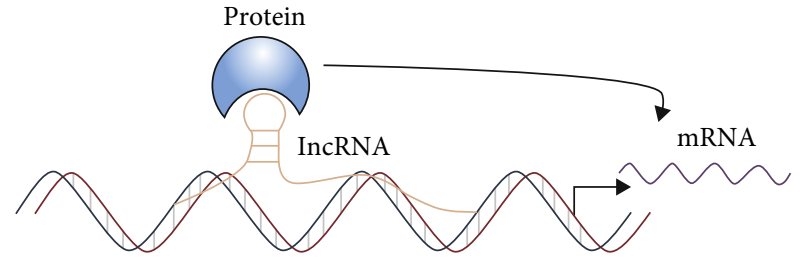

(e)

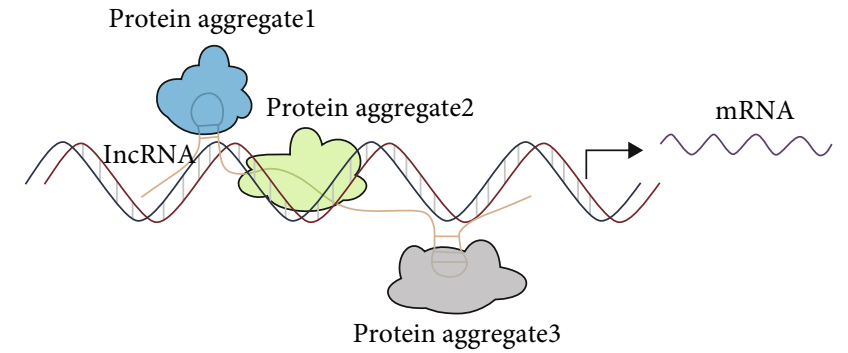

(f)

FIGURE 1: The modes of action of lncRNA. (a) lncRNAs function as signals to directly regulate the transcription of the downstream gene. (b) lncRNAs function as decoys to regulate the binding of proteins to DNA or other proteins. (c) lncRNAs interact with miRNA as miRNA sponges. (d) lncRNAs regulate alternative splicing. (e) lncRNAs serve as guide RNAs to impart specificity at genomic positions through either RNA-DNA or RNA-protein-DNA interactions. (f) lncRNAs serve as scaffolds to allow the formation of larger RNA-protein complexes.

accumulation of $\beta$-amyloid plaques and neurofibrillary tangles by degrading these aggregates in the early stages of $\mathrm{AD}$, while the promotion of autophagy could aggravate the impaired autophagosome-lysosomal fusion and lysosomal dysfunction the late stages of $\mathrm{AD}$ [39]. Despite great advances in diagnostic and therapeutic drugs of $\mathrm{AD}$ in recent years, there are no effective treatments to prevent or reverse $\mathrm{AD}$ progression. Hence, understanding the regulatory mechanisms underlying autophagy will be the focus of treatment for AD. Recent studies found that lncRNAs were differentially expressed in the blood and CSF from patients with $\mathrm{AD}$ compared to the healthy elderly and played a key role in $\mathrm{AD}$ pathogenesis [40]. Nevertheless, there are few reports about the role and molecular mechanism of IncRNAs on autophagy in $\mathrm{AD}$; here, we introduce lncRNAs involved in autophagy regulation in the $\mathrm{AD}$, which contributes to $\mathrm{AD}$ pathogenesis and provides new diagnostic biomarkers or therapeutic targets for $\mathrm{AD}$.

3.1.1. IncRNA 17A. IncRNA $17 \mathrm{~A}$ is transcribed from the antisense strand of the GABABR2 gene and expressed in the human brain. Massone et al. suggested that the expression of IncRNA 17A was upregulated in the brain tissue of patients with $\mathrm{AD}$ and regulated $\mathrm{A} \beta$ secretion [41]. Wang et al. found that compared to lncRNA 17A overexpressed cells, IncRNA 17A knockdown increased the expression levels of LC3-II which is a hallmark of autophagosome formation. At the same time, the level of $A \beta 42$ was diminished in shRNA-17A-transfected SH-SY5Y cells. A $\beta 42$ is considered the main component of senile plaques and the primary mechanistic factor in AD pathology. Moreover, GABABR2 was found to be upregulated when IncRNA 17A was overexpressed and downregulated when lncRNA was knocked down. Therefore, the researchers speculated that depletion of lncRNA 17A promoted autophagy by regulating alternative splicing of GABABR2 and thus alleviated the accumulation of protein aggregates, which effectively suppress the progression of $\mathrm{AD}$ [42]. However, the effects of lncRNA $17 \mathrm{~A}$ are needed to be examined in vivo.

3.1.2. IncRNA NEAT1. IncRNA NEAT1 has been reported to be a vital transcriptional regulator in cancer cell growth [43]. NEAT1 was well documented to be upregulated in the brain tissue from patients with $\mathrm{AD}$, and its role in the pathophysiology of $\mathrm{AD}$ has received much attention in recent years [44, 45]. IncRNA NEAT1 is significantly upregulated in old APP/PS1 mice (over 6 months old) in a time-dependent manner but not in younger littermates, and the levels of $A \beta$ 
TABLE 1: lncRNAs associated with autophagy regulation in neurological diseases.

\begin{tabular}{|c|c|c|c|c|c|c|c|}
\hline $\begin{array}{l}\text { Neurological } \\
\text { diseases }\end{array}$ & $\operatorname{lncRNA}$ & Main target gene & Expression & Mechanism & Function & Models & Ref. \\
\hline \multirow{2}{*}{$\begin{array}{l}\text { Alzheimer's } \\
\text { disease }\end{array}$} & $17 \mathrm{~A}$ & GABABR2 & Up & $\begin{array}{l}\text { 17A downregulation promotes } \\
\text { autophagy by elevating } \\
\text { GABABR2 expression }\end{array}$ & $\begin{array}{c}\text { Inducing } \mathrm{A} \beta \\
\text { secretion and } \\
\text { increment of the } \\
\mathrm{A} \beta 42 / 40 \text { ratio }\end{array}$ & $\begin{array}{l}\text { SH-SY5Y cells } \\
\text { treated with } \\
\text { amyloid } \beta \\
\text { peptide1-42 }\end{array}$ & $\begin{array}{l}{[41,} \\
42]\end{array}$ \\
\hline & NEAT1 & $\begin{array}{l}\text { NEDD4L and } \\
\text { PINK1 }\end{array}$ & Up & $\begin{array}{c}\text { Inhibiting PINK1- } \\
\text { independent mitophagy by } \\
\text { promoting NEDD4L-mediated } \\
\text { PINK1 ubiquitination and } \\
\text { degradation }\end{array}$ & $\begin{array}{l}\text { Increasing } \mathrm{A} \beta \\
\text { accumulation }\end{array}$ & APP/PS1 mice & [46] \\
\hline \multirow{7}{*}{$\begin{array}{l}\text { Parkinson's } \\
\text { disease }\end{array}$} & NEAT1 & PINK1 & Up & $\begin{array}{l}\text { Promoting autophagy through } \\
\text { stabilizing PINK1 protein }\end{array}$ & $\begin{array}{c}\text { Alleviating } \\
\text { dopaminergic } \\
\text { neuronal injury }\end{array}$ & $\begin{array}{l}\text { MPTP mouse } \\
\text { model and } \\
\text { MPP } \\
\text { +-induced } \\
\text { SH-SY5Y }\end{array}$ & [51] \\
\hline & SNHG1 & miR-221/222 & Up & $\begin{array}{l}\text { SNHG1 downregulation } \\
\text { increased LC3-II levels } \\
\text { through the miR- } \\
221 / 222 / \text { p27/mTOR pathway }\end{array}$ & $\begin{array}{l}\text { Enhancing } \alpha \text { - } \\
\text { synuclein } \\
\text { aggregation thus } \\
\text { leads to } \\
\text { dopaminergic } \\
\text { toxicity }\end{array}$ & $\begin{array}{l}\text { MPTP mouse } \\
\text { model and } \\
\text { MPP } \\
\text { +-induced } \\
\text { MN9D cells }\end{array}$ & [56] \\
\hline & & LRRK2 & & $\begin{array}{l}\text { Promoting autophagy by } \\
\text { improving LRRK2 mRNA } \\
\text { stability and activating } \\
\text { ERK/MAPK pathways }\end{array}$ & $\begin{array}{l}\text { Increasing the loss } \\
\text { of striatal dopamine } \\
\text { and promoting PD } \\
\text { progression }\end{array}$ & $\begin{array}{l}\text { MPTP mouse } \\
\text { model and } \\
\text { MPP } \\
\text { +-induced } \\
\text { SH-SY5Y }\end{array}$ & [57] \\
\hline & HUIAIK & miR-126-5p & & $\begin{array}{l}\text { Suppressing autophagy trough } \\
\text { HOTAIR/miR-126- } \\
\text { 5p/RAB3IP axis }\end{array}$ & $\begin{array}{l}\text { Elevating the loss of } \\
\text { striatal dopamine } \\
\text { and the } \\
\text { accumulation of } \alpha \text { - } \\
\text { synuclein }\end{array}$ & $\begin{array}{l}\text { MPTP rat } \\
\text { model and } \\
\text { MPP } \\
\text { +-induced } \\
\text { SH-SY5Y }\end{array}$ & [59] \\
\hline & HAGLROS & miR-100 & Up & $\begin{array}{c}\text { Inhibiting autophagy via } \\
\text { regulating miR-100/ATG10 } \\
\text { axis and PI3K/AKT/mTOR } \\
\text { pathway activation }\end{array}$ & $\begin{array}{l}\text { Contributing to the } \\
\text { development of PD }\end{array}$ & $\begin{array}{l}\text { MPTP mouse } \\
\text { model and } \\
\text { MPP } \\
\text { +-induced } \\
\text { SH-SY5Y }\end{array}$ & [61] \\
\hline & H19 & DUSP5 & Up & $\begin{array}{l}\text { Promoting autophagy through } \\
\text { regulating DUSP5-ERK1/2 } \\
\text { axis }\end{array}$ & $\begin{array}{l}\text { Aggravating } \\
\text { cerebral ischemia- } \\
\text { reperfusion injury }\end{array}$ & $\begin{array}{l}\text { SH-SY5Y cell } \\
\text { culture }\end{array}$ & [71] \\
\hline & SNHG12 & Unknown & Up & $\begin{array}{l}\text { Activating beclin1-dependent } \\
\text { autophagy }\end{array}$ & $\begin{array}{l}\text { Alleviating cerebral } \\
\text { ischemia- } \\
\text { reperfusion injury }\end{array}$ & $\begin{array}{l}\text { SH-SY5Y cell } \\
\text { culture }\end{array}$ & [76] \\
\hline \multirow{4}{*}{$\begin{array}{l}\text { Ischemic } \\
\text { stroke }\end{array}$} & & miR-26b & & $\begin{array}{l}\text { Activating autophagy through } \\
\text { upregulation of ULK2 }\end{array}$ & Attenuating & & [74] \\
\hline & MALAT1 & miR-200c-3p & Up & $\begin{array}{l}\text { Promoting autophagy by } \\
\text { regulating miR-200c-3p/Sirt1 } \\
\text { axis }\end{array}$ & $\begin{array}{l}\text { ischemia- } \\
\text { reperfusion injury }\end{array}$ & BMEC culture & [75] \\
\hline & & miR-30a & & $\begin{array}{l}\text { Promoting autophagy via } \\
\text { MALAT1/miR-30a/beclin1 } \\
\text { axis }\end{array}$ & $\begin{array}{l}\text { Aggravating } \\
\text { ischemic injury }\end{array}$ & $\begin{array}{l}\text { Mouse brain } \\
\text { and N2a cells }\end{array}$ & [73] \\
\hline & KCNQ1OT1 & miR-200a & Up & $\begin{array}{l}\text { Promoting the formation of } \\
\text { autophagosomes through the } \\
\text { mir-200a/FOXO3/ATG7 axis }\end{array}$ & $\begin{array}{l}\text { Aggravating } \\
\text { neurological } \\
\text { impairments }\end{array}$ & $\begin{array}{l}\text { Mouse brain } \\
\text { and SH-SY5Y } \\
\text { cell culture }\end{array}$ & {$[78]$} \\
\hline Epilepsy & MALAT1 & PI3K/AKT & Up & $\begin{array}{c}\text { Activating autophagy by } \\
\text { inhibiting PI3K/AKT signaling } \\
\text { pathway }\end{array}$ & $\begin{array}{l}\text { Promoting the } \\
\text { degeneration and } \\
\text { necrosis of }\end{array}$ & Rats with EP & [81] \\
\hline
\end{tabular}


TABle 1: Continued.

\begin{tabular}{|c|c|c|c|c|c|c|c|}
\hline $\begin{array}{l}\text { Neurological } \\
\text { diseases }\end{array}$ & $\operatorname{lncRNA}$ & Main target gene & Expression & Mechanism & Function & Models & Ref. \\
\hline \multirow{10}{*}{ Glioma } & \multirow{4}{*}{ MEG3 } & & \multirow{4}{*}{ Down } & \multirow{3}{*}{$\begin{array}{l}\text { Activating autophagy by } \\
\text { downregulating of the } \\
\text { PI3K/AKT/mTOR pathways } \\
\text { and the upregulating of Sirt7 }\end{array}$} & $\begin{array}{l}\text { hippocampal } \\
\text { neurons }\end{array}$ & & \\
\hline & & PI3K/AKT/mTOR & & & \multirow[t]{2}{*}{$\begin{array}{l}\text { Repressing cell } \\
\text { proliferation and } \\
\text { migration }\end{array}$} & \multirow[t]{2}{*}{ U251 cell lines } & \multirow[t]{2}{*}[92]{} \\
\hline & & & & & & & \\
\hline & & Unknown & & $\begin{array}{l}\text { Suppressing cisplatin-induced } \\
\text { excessive autophagy }\end{array}$ & $\begin{array}{l}\text { Increasing glioma } \\
\text { cell sensitive to } \\
\text { cisplatin }\end{array}$ & U87 cell lines & [93] \\
\hline & PVT1 & miR-186 & Up & $\begin{array}{l}\text { Activating autophagy through } \\
\text { upregulation of ATG7 and } \\
\text { Beclin1 }\end{array}$ & $\begin{array}{l}\text { Promoting } \\
\text { proliferation, } \\
\text { migration and } \\
\text { angiogenesis }\end{array}$ & hCMEC/D3 & [94] \\
\hline & \multirow{4}{*}{ MALAT1 } & \multirow{3}{*}{ miR-101 } & \multirow{4}{*}{ Up } & $\begin{array}{l}\text { Activating autophagy through } \\
\text { upregulation }\end{array}$ & \multirow{3}{*}{$\begin{array}{l}\text { Promoting cell } \\
\text { proliferation }\end{array}$} & $\begin{array}{l}\text { Glioma tissue } \\
\text { from patients, }\end{array}$ & \multirow{3}{*}[96]{} \\
\hline & & & & & & U251, U373, & \\
\hline & & & & STMN1, RAB5A, and ATG4D & & $\begin{array}{l}\text { and D247 cell } \\
\text { lines }\end{array}$ & \\
\hline & & miR-384 & & $\begin{array}{l}\text { Activating autophagy through } \\
\text { upregulation GOLM1 }\end{array}$ & $\begin{array}{l}\text { Enhancing glioma } \\
\text { migration and } \\
\text { invasion }\end{array}$ & $\begin{array}{l}\text { Glioma tissue } \\
\text { from patients, } \\
\text { SHG-44, and } \\
\text { LN229 cells }\end{array}$ & {$[100$} \\
\hline & GAS5 & mTOR & Up & $\begin{array}{l}\text { Suppressing cisplatin-induced } \\
\text { excessive autophagy in an } \\
\text { mTOR-independent manner }\end{array}$ & $\begin{array}{l}\text { Increasing glioma } \\
\text { cell sensitive to } \\
\text { cisplatin }\end{array}$ & $\begin{array}{l}\text { U87 and u138 } \\
\text { cell lines }\end{array}$ & {$[103$} \\
\hline
\end{tabular}

showed a similar expression pattern. A further study found that overexpression of lncRNA NEAT1 could improve the interaction of PINK1 and NEDD4L and facilitate PINK1 ubiquitination. Besides, protein levels of the autophagy adaptors such as P62, OPTN, and LC3 were decreased at the same time $\mathrm{A} \beta$ was increased. Furthermore, lncRNA NEAT1 knockdown can reverse the above-mentioned changes and ameliorates cognitive impairments in $\mathrm{AD}$ mice. These studies suggested that IncRNA NEAT1 can promote NEDD4Lmediated PINK1 ubiquitination and degradation and thus inhibit PINK1-dependent mitophagy, which finally escalates $\mathrm{A} \beta$ accumulation and cognitive decline [46]. It is well known that PINK1 together with Parkin can promote the recruitment of autophagy receptor OPTN and activate ubiquitin and autophagic proteins, contributing to the information of autophagosome [47]. From what has been discussed above, lncRNA NEAT1 aggravated $\mathrm{A} \beta$-induced neuronal damage via promoting the ubiquitination and degradation of PINK1. Hence, lncRNA NEAT1 may be a useful biomarker for AD.

\subsection{IncRNA-Mediated Autophagy in Parkinson's Disease. PD} is the second most common neurodegenerative disorder after $\mathrm{AD}$ in aging individuals, the main characteristics of which are the progressive loss of dopaminergic neurons in the substantia nigra pars compacta and the formation of Lewy bodies within the cytoplasm, leading to motor dysregulation [48, 49]. Although the pathogenesis remains not fully understood, PD is widely assumed to be associated with both genetic and environmental factors [35]. Most PD cases are sporadic with an unclear etiology, but about $5 \%$ are familiar caused by genic mutations, including SNCA, LRRK2, PRKN, PINK1, MAPT, GBA, and PARK2 [50]. Mutations in these genes can cause the formation of cytotoxic aggregates, impaired actin remodeling, dysregulation of autophagy, and enhancement of proapoptotic signaling pathways and eventually lead to neuron degeneration. Recently, growing evidences indicated that $\ln \mathrm{RNA}$ takes part in the pathogenesis of $\mathrm{PD}$. In the following paragraphs, we focus on the role of lncRNA-mediated autophagy in PD.

3.2.1. $\ln R$ RNA NEAT1. Similar to its role in AD, lncRNA NEAT1 has also been proved to play key roles in PD pathophysiology. MPTP can significantly promote the expression level of lncRNA NEAT1, PINK1, and LC3-II in vitro and in vivo models of $\mathrm{PD}$, which also seems to increase with dose and time within a certain range $[51,52]$. Upregulated NEAT1 expression can further increase PINK1 expression level by inhibiting CHX-induced PINK1 protein degradation, which occurs both in impaired and in intact mitochondria. Moreover, the downregulation of NEAT1 largely reversed the effect of MPP+ on SH-SY5Y cells, including decreased LC3II and PINK1 protein levels. The accumulated PINK1 directly interacts with LC3-II and increases the accumulation of LC3-II in mitochondria, leading to abnormal mitochondrial autophagy [51]. Interestingly, the NEAT1/PINK1/ LC3-II axis is involved not only in the degradation of 
damaged mitochondria in PD models but also in the abnormal elimination of the healthy mitochondria leading to reduced ATP generation thereby causing neurodegeneration [53]. The above results indicated that lncRNA NEAT1 could induce abnormal autophagy by stabilizing PINK1 which was an LC3-II upstream regulatory factor and played a role in the pathogenesis of PD.

3.2.2. $\ln c R N A S N H G 1$. It has been reported that the expression level of lncRNA SNHG1 was significantly upregulated in postmortem midbrain samples from PD patients compared to healthy people [54]. Besides, lncRNA SNHG1 also has been demonstrated to promote $\alpha$-synuclein aggregation and enhance neurotoxicity resulting in dopaminergic neuronal loss [55]. Recent studies have found lncRNA SNHG1 gradually upregulated in cell and animal models in PD. Furthermore, silencing lncRNA SNHC1 could remarkably increase the expression of miR-221/222 and LC3-II and prevent MPP+-induced cell death. Further investigations indicated that IncRNA SNHG1 acted as a ceRNA and prevented miR-221/222 from interacting with target P27 mRNA which is a key regulatory factor for the phosphorylation of mTOR and cell death. The decreased expression of P27 can inhibit the mTOR pathway, thus promoting neural autophagy and alleviating MPP+-mediated cell injury [56]. Experiment result shows that downregulated lncRNA SNHG1 inhibits the mTOR pathway and initiates autophagy through sponging miR-221/222, which can reduce the death of dopaminergic neurons in PD patients.

3.2.3. $\ln c R N A$ HOTAIR. Several studies have indicated that lncRNA HOTAIR obviously increased in vivo and vitro models of PD [1, 57]. As previously mentioned, mutations of LRRK2 are associated with familial PD and they can enhance autophagy by activating the ERK/MAPK pathway [58]. Overexpression of lncRNA HOTAIR could specifically improve LRRK2 mRNA stability and upregulate its expression, which promoted autophagy in PD models. On the contrary, silencing HOTAIR would rescue these alterations and increase cell viability [57]. These results strongly indicated that lncRNA HOTAIR can activate the ERK/MAPK pathway through improving the stability of LRRK2, which can inhibit autophagy and ultimately lead to PD. Recently, Lin et al. found that IncRNA HOTAIR was upregulated in MPP +-treated SH-SY5Y cell lines and contribute to PD while downregulating HOTAIR would increase the number of TH-positive cells and decrease the number of $\alpha$-synucleinpositive cells. Similar results were also observed in in vivo experiments. A further study showed that miR-126-5p negatively regulated the expressions of RAB3IP which have been demonstrated to inhibit autophagy in mammalian cells. lncRNA HOTAIR could prevent miR-126-5P from interacting with RAB3IP by sponging miR-126-5P, which would inhibit autophagy and eventually caused the accumulation of $\alpha$-synuclein in dopaminergic neurons [59]. Overall, the lncRNA HOTAIR/miR-126-5p/RAB3IP axis has been proved to be related to autophagy in $\mathrm{PD}$, and its dysregulation was considered a therapeutic target for PD.
3.2.4. $\ln c R N A$ HAGLROS. A recent study showed that lncRNA HAGLROS was upregulated and miR-100 was downregulated in MPTP-induced mice and MPP+-treated SH-SY5Y cells. Knockdown of IncRNA HAGLROS could increase the expression level of miR-100 and alleviated MPTP-induced autophagy. A further study found that ATG 10 which participated in the formation of autophagosomes and initiated autophagy was a direct target of miR-100 [60]. lncRNA HAGROS could prevent miR-100 from interacting with ATG10 by serving as a sponge of miR-100 and thus promote autophagy, leading to aggravating MPP+-induced cell injury. In addition, the $\mathrm{PI} 3 \mathrm{~K} / \mathrm{AKT} / \mathrm{mTOR}$ pathway was found to be inactivated in MPP+-intoxicated SH-SY5Y cell, which led to the decrease in the number of dopaminepositive cells and aggravated cell damage; meanwhile, IncRNA HAGLROS silencing could dramatically increase the phosphorylation levels of the PI3K/AKT/mTOR pathway and thus promote autophagy, contributing to protecting neurons from MPTP-induced damage [61]. Together, lncRNA HAGLROS regulates autophagy through regulating miR100/ATG10 axis and PI3K/AKT/mTOR, which provide a potential therapeutic strategy for $\mathrm{PD}$ and need further evidence.

3.3. IncRNA-Mediated Autophagy in Ischemic Stroke. IS is a generic term for blood flow interruption and cerebral tissue necrosis caused by a thrombotic or embolic blockage of a cerebral artery, accounting for approximately $85 \%$ of all strokes $[62,63]$. After brain ischemia, nerve cell membrane potential and cellular ion homeostasis are disrupted leading to a series of deleterious events in the brain such as excitotoxicity, oxidative stress, autophagy, and inflammation. These events affect each other, forming a positive feedback loop and causing ischemic cascading effects, which causes irreversible neuronal injury characterized by neuronal apoptosis or death in the core area, brain edema, and bloodbrain barrier dysfunction $[64,65]$. The current research indicated that autophagy was activated after cerebral ischemia; at this time, inhibition of autophagy plays a protective role whereas excessive activation of autophagy aggravates the injury. However, the inhibition of basal autophagy before ischemic stroke can aggravate subsequent cerebral ischemic injury $[66,67]$. Therefore, autophagy induction may be a potential therapeutic target for IS [68]. We will review some regulatory $\operatorname{lncRNAs}$ on autophagy in IS in this section.

3.3.1. $\ln c R N A$ H19. IncRNA H19, a maternally imprinted gene, generally declines after birth, whereas it increases in pathological situations such as cancer, oxidative stress, or hypoxia, which is important for early embryonic development [69]. The expression levels of lncRNA H19 are dramatically increased in the peripheral blood of ischemic patients and brain tissue, plasma, and white blood cells of mice with transient cerebral ischemia. Wang et al. found that compared to the control group, the human neuroblastoma cell line $\mathrm{SH}$ SY5Y subjected to oxygen-glucose deprivation/reoxygenation $(\mathrm{OGD} / \mathrm{R})$ significantly induced the expression of lncRNA H19, and at the same time, the ratio of LC3II/I and beclin1 was increased, while P62 was decreased. 
Knocking out lncRNA h19 has been reported to reverse these changes. Further studies have shown that the overexpression of lncRNA H19 can activate autophagy by inhibiting DUSP5, a mitogen-activated protein kinase phosphatase, and thus activating ERK1/2 which is related to autophagy initiation $[70,71]$. Taken together, lncRNA H19 can promote autophagy through regulating the DUSP5-ERK1/2 axis, contributing to cerebral ischemia-reperfusion injury. However, these results still need to be further verified by in vivo experiments.

3.3.2. IncRNA MALAT1. IncRNA MALAT1 was considered to be one of the most significantly upregulated lncRNAs in both in vivo and in vitro models of IS, accompanied by the upregulation of LC3-II and Beclin1 [72, 73]. Further studies by Guo et al. showed that IncRNA MALAT1 decreases Beclin1 expression by acting as a sponge for miR-30a and thus promotes Beclin1-dependent autophagy, leading to neuronal cell death after IS. Moreover, IncRNA MALAT1 silencing can alleviate ischemic brain injury by inhibiting autophagy. This suggests that the MALAT1/miR-30a/beclin1 (lncRNA/miRNA/mRNA) regulatory network may exist in ischemic stroke [73]. Interestingly, IncRNA MALAT1 and autophagy have a protective effect on BMECs during IS. MALAT1 functions as a ceRNA for miR-26b, which can promote ULK2 expression. ULK2 is a downstream target in the mTOR signaling pathway and is associated with autophagosome formation, suggesting that MALAT1 protected BMECs from ischemia-reperfusion injury by promoting autophagy [74]. Another study by Wang et al. reported that the in vitro BMEC model, IncRNA MALAT1, also serves as ceRNA and prevents miR-200c-3p from binding to Sirt1 which has been reported to stimulate the expression and deacetylation of autophagy-related genes, suggesting that lncRNA MALAT1 can activate autophagy and promote the survival of OGD/R-treated BMECs by regulating miR-200c3p/Sirt1 [75]. Collectively, IncRNA MALAT1 can regulate autophagy in IS through sponging miRNA and abolishing their effects on autophagy-related factors.

3.3.3. $\ln$ RNA SNHG12. Recently, IncRNA SNHG12 was found to be significantly elevated in mouse MCAO models and OGD/R models in SH-SY5Y cells $[72,76]$. An in vitro study has confirmed that overexpression of IncRNA SNHG12 could promote LC3-II and Beclin1 expression levels and the survival of SH-SY5Y cell lines after OGD/R, while downregulation of SNHG12 rescued these effects. Besides, autophagy inhibitor 3-MA can weaken the protective effect of lncRNA SNHG12 overexpression on I/R injury, suggesting that lncRNA SNHG12, as an autophagy inducer, can attenuate brain I/R injury and may be a new therapeutic target for ischemic stroke [76]. Does lncRNA SNHG12 regulate mTOR, a classical autophagy signaling pathway, or autophagy-related proteins? The mechanisms of lncRNA SNHG12 on autophagy following IS remain to be elucidated.

3.3.4. IncRNA KCNQ10T1. IncRNA KCNQ1OT1 is significantly upregulated in the peripheral blood of patients with ischemic stroke. Previous studies have shown that lncRNA KCNQ1OT1 is associated with risk factors for ischemic stroke, such as diabetes and myocardial infarction [77]. A recent study substantiated that lncRNA KCNQ1OT1 silencing reduced cerebral infarction volume and alleviated neurological deficits in mouse MCAO models as well as improved cell viability of OGD/R-treated SH-SY5Y cells. Besides, rapamycin, an autophagy inducer, reversed these effects, suggesting that the downregulation of IncRNA KCNQ1OT1 protects neurons from ischemia injury by inhibiting autophagy. Further studies found that lncRNA KCNQ1OT1 may be the ceRNA of miR-200a and prevented targeting of FOXO3 and thus promoted the expression of ATG7 which participates in vesicle elongation. These experiments indicated that the knockdown of KCNQ1OT1 may inhibit the formation of autophagosomes through the miR-200a/FOXO3/ATG7 axis and increase cell viability. This finding provides a potential novel strategy for the treatment of ischemic stroke [78].

3.4. IncRNA-Mediated Autophagy in Epilepsy. Epilepsy (EP), as one of the most common neurological disorders, is a kind of chronic syndrome mainly caused by abnormal discharge of brain neurons [79]. It is characterized by spontaneous seizures with a high recurrence rate of $60 \%$. Despite the availability of antiepileptic drugs (AEDs), many patients still suffer refractory seizures and unacceptable side effects [80]. Currently, the pathogenesis of epilepsy has not been well defined and the reports about the role of autophagy in epilepsy remain rare. Wu et al. showed that IncRNA MALAT1 was obviously upregulated in the hippocampus of rats with EP and the expression of LC3II/LC3I and Beclin1 also upregulated compared to the control group, indicating that EP may lead to excessive autophagy in hippocampal neurons of rats [81]. In addition, further mechanism analysis showed that lncRNA MALAT1 activated autophagy by inhibiting PI3K/AKT signaling pathway while silencing MALAT1 could prohibit autophagy in hippocampal neurons of epileptic models. These results bring up a hint that downregulated lncRNA MALAT1 can protect the hippocampal neurons from excessive autophagy through activating PI3K/AKT signaling pathway, contributing to attenuating neuron injury after EP. These findings may help to elucidate the pathophysiology of epilepsy and provide a potential therapeutic target.

3.5. IncRNA-Mediated Autophagy in Glioma. Glioma has been considered to be the most common type of primary brain tumor with high mortality and poor prognosis, accounting for $30 \%$ of central nervous system tumors and $80 \%$ of all malignant brain tumors [82]. The growth and metastasis of glioma rely on angiogenesis, which is one of the main reasons for treatment failure [83]. Cisplatin, a chemotherapeutic agent, binds to DNA and causes DNA damage-induced tumor cell death, which is extensively used for the treatment of glioma currently [84]. The role of autophagy in cancer varies from person to person. On the one hand, autophagy contributes to maintaining cellular homeostasis and can suppress tumor growth; on the other hand, autophagy may also facilitate proliferation and survival of tumor cells thus promoting tumor growth, invasion, and metastasis $[85,86]$. In recent years, more and more studies have shown that autophagy played a key role in the 
development of tumors, including cell proliferation, metastasis, and chemotherapy resistance [87].

Interestingly, the latest evidence suggested that lncRNAs are involved in the development and cisplatin sensitivity of glioma through regulating autophagy. In the following paragraphs, we will discuss the regulatory lncRNAs in autophagy during glioma development and their specific mechanisms to explore a more suitable therapeutic target for treating glioma.

3.5.1. IncRNA MEG3. IncRNA MEG3 is widely recognized as a tumor suppressor gene in several types of human cancers. lncRNA MEG3 was found to be markedly downregulated in glioma tissues and cell lines, which is an independent biomarker of poor prognosis in glioma [88]. It usually functioned as a ceRNA; for example, it could prevent miR-19a and miR-93 from interacting with their target mRNAs and elevate the expression levels of PTEN and PHLPP2 respectively, which inhibited PI3K/AKT/mTOR pathway and eventually suppressed the proliferation of glioma $[89,90]$. Xu et al. revealed that overexpression of $\operatorname{lncRNA}$ MEG3 repressed cell proliferation and migration but promoted autophagy in U251 cells. Beclin1 and LC3-II/LC3-I were upregulated whereas P62 was downregulated; interestingly, these autophagy-related proteins' expressions were still unchanged after lncRNA MEG3 silencing, suggesting that autophagy in U251 cells was induced by inhibiting autophagosome degradation after overexpression of lncRNA MEG3, and inhibition of autophagy can improve cell viability. Furthermore, lncRNA MEG3 overexpression decreased the phosphorylation levels of key kinases in PI3K/AKT/mTOR pathways, indicating the inactivation of the PI3K/AKT/mTOR pathways and the upregulation of Sirt7 that is related to the deacetylation of autophagy- related genes and participated in various types of cancers [91]. However, IncRNA MEG3 or Sirt7 silencing exhibited the utter opposite effects. Collectively, lncRNA MEG3 decreased the phosphorylation levels of PI3K/AKT/mTOR pathways by enhancing Sirt7 and finally activates autophagy and improves the prognosis of glioma [92]. These results may provide novel strategies of glioma treatment, but the specific molecular mechanisms between MEG3 and Sirt7 require further investigation, and the functional role of MEG3 needs to be verified in in vivo experiments for future clinical application.

Another study showed that the expression levels of lncRNA MEG3 in U87 cells were induced by cisplatin in a time- and dose-dependent manner. Overexpression of lncRNA MEG3 enhanced the chemosensitivity of U87 cell lines to cisplatin through inhibiting cisplatin-induced autophagy, whereas knockdown of lncRNA MEG3 increased resistance of U87 cell lines to cisplatin by promoting cisplatin-induced autophagy [93]. These studies suggest that lncRNA MEG3 may be a potential target for the treatment of cisplatin-resistance glioma.

3.5.2. IncRNA PVTI. A recent study found that lncRNA PVT1 was upregulated in glioma vascular endothelial cells and miR-186 was downregulated. Moreover, lncRNA PVT1 overexpression or miR-186 knockdown increased the expression levels of ATG7, Beclin-1, and LC3-II/LC3-I whereas it decreased the level of P62, contributing to cell proliferation, migration, and angiogenesis. Meanwhile, autophagy inhibitors could reverse these effects. Further mechanism analysis suggested that lncRNA PVT1 was bound to miR-186 directly and abolished its negative effects of ATG7 and Beclin-1 which is essential for autophagy initiation and the formation of a double-membrane structure. These studies are a hint that lncRNA PVT1 induces autophagy and thus promotes proliferation, migration, and angiogenesis of glioma-conditioned vascular endothelial cells through regulating miR-186ATG7/Beclin-1 expression [94]. IncRNA PVT1 and miR186 would provide an antiangiogenic target for gliomas.

3.5.3. $\ln C R N A$ MALAT1. It has been reported that lncRNA MALAT1 was highly expressed in glioma tissue and served as an indicator for poor prognosis in glioma patients; however, the regulatory mechanism of lncRNA MALAT1 in human glioma was rarely studied [95]. Recently, IncRNA MALAT1 was found to be highly expressed in glioma tissues compared with adjacent normal tissues, and its elevated expression was positively associated with the LC3-II level. In vitro experiments also showed that lncRNA Malat1 significantly promoted autophagy and proliferation of glioma cells. More importantly, the inhibition of autophagy by 3-MA alleviated MALAT1-induced glioma proliferation, suggesting that lncRNA MALAT1 could activate autophagy and eventually promote glioma proliferation. Further molecular mechanism analysis revealed that lncRNA MALAT1 could directly bind to miR-101 and prevent it from interacting with the $3^{\prime}$ -UTR of STMN1, RAB5A, and ATG4D mRNA [96]. STMN1, RAB5A, and ATG4D were shown to be important autophagic regulators. STMN1 and RAB5A affected the fusion of autophagosomes with lysosomes, whereas ATG4D participated in autophagosome maturation [97-99]. These experimental results demonstrated that lncRNA MALAT1 promoted autophagy and proliferation of glioma cells by regulating the Malat1-miR-101-STMN1/RAB5A/ATG4D network [96]. In the latest study, IncRNA MALAT1 also acted as a miRNA sponge to regulate autophagy in glioma cells. Knockdown of lncRNA MALAT1 could depress glioma cell autophagy, migration, and invasion, whereas inhibiting miR-384 could eliminate these effects [100]. Besides, GOLM1, a downstream target of miR-384, was also identified to promote autophagy by activating protein kinase AKT [101], suggesting that lncRNA MALAT1, as a miR-384 sponge, promoted vesicle nucleation and thus enhanced glioma migration and invasion by upregulating GOLM1 [100]. This newly discovered IncRNA MALAT1/miR384/GOLM1 axis may provide new insights into the mechanisms of glioma metastasis, and lncRNA MALAT1 may be a promising target for future glioma therapy.

3.5.4. IncRNA GAS5. It has been reported that lncRNA GAS5 suppressed glioma stem cell proliferation and high expression level of lncRNA GAS5 was associated with the 2-year overall survival rate of patients with glioma [102]. Recently, a study showed that IncRNA GAS5 downregulation reduced the sensitivity of U87 cells that had high GAS5 levels to cisplatin. In contrast, IncRNA GAS5 overexpression reduced 
U138 cells that had a relatively low GAS5 levels resistance to cisplatin. These results suggested that lncRNA GAS5 may increase the sensitivity of glioma cells to cisplatin and play an important role in glioma chemoresistance. A Further mechanism study revealed that exposure to cisplatin could increase the expression levels of LC3II and decrease P62 levels, thus leading to excessive autophagy. In addition, upregulated lncRNA GAS5 activated mTOR signaling that was restrained by cisplatin and eventually inhibited cisplatin-induced excessive autophagy. Interestingly, blocking the mTOR pathway could also overturn the positive effect of IncRNA GAS5 upregulation on chemosensitivity to cisplatin. However, how IncRNA GAS5 regulates the mTOR signaling pathway needs to be further studied. In a word, lncRNA GAS5 suppressed cisplatin-induced excessive autophagy and thus increased cisplatin sensitivity in an mTOR-independent manner, suggesting that IncRNA GAS5 was a potential and promising target for overcoming glioma chemoresistance [103].

\section{Conclusion and Perspectives}

The above-mentioned studies have corroborated the involvement of lncRNAs in autophagy and have opened the way for further investigations into the function and mechanism of lncRNAs in neurological diseases. At present, RNA-targeted or RNA-based therapeutic approaches include antisense oligonucleotides (ASOs), RNA interference (RNAi), and ribozymes with intrinsic catalytic activities and RNA aptamers [104]. It was shown that ASOs regulated noncoding RNAs via the following two main methods. One is to synthesize antagonists to inhibit noncoding RNAs binding to their mRNA targets. The other use of ASOs is to prepare miRNA mimetics to restore levels of miRNAs that have been reduced in pathogenic conditions [105]. In 2016, two ASOs, eteplirsen and nusinersen, were approved by the FDA for the treatment of Duchenne muscular dystrophy and spinal muscular atrophy respectively, which opened a new era of ASO therapies for neurodegenerative diseases [106]. Currently, a phase 1 clinical trial of a MAPT-targeting ASO and LRRK2 ASO BIIB094 has been initiated in mild AD patients (NCT03186989) and PD patients (NCT03976349), respectively. Unlike ASO therapeutics which can be ended by terminating treatment, RNAi-based therapeutics when delivered as an shRNA can develop nonreversible efficacy, which may be beneficial but also comes with risk since it may cause a decrease in untargeted proteins [107]. A growing body of evidence points towards the promise of nanoparticles as carriers for siRNA and shRNA therapeutics for neurodegenerative disorders, including shRNAs targeting a $\alpha$-synuclein in a mouse model of PD, siRNAs targeting BACE1 and APP in mouse CNS toward treating AD [104]. Nevertheless, these promising RNA-based therapies also face substantial challenges. Firstly, most RNA-targeted drugs cannot cross the blood brain barrier and has to be delivered to the central nervous system through intrathecal injection, an invasive delivery method that limits its use. Secondly, it is well known that lncRNA has a variety of biological functions and complex potential mechanisms; however, at present, studies on the mechanism of lncRNA are generally limited to finding relevant miRNA or binding proteins, not to mention poor conservation of IncRNA among species. Lastly, neurons possess limited ability to regenerate so that considerable undetected and potentially irreversible damage is likely to have occurred before a patient reports symptom to a physician, which requires us to find reliable biomarkers for early diagnosis and treatment. For example, in vivo and in vitro, certain IncRNA dynamically changes over ischemia time, and thus, the level of lncRNA in blood samples may reflect the pathophysiological state of the brain, which may be used as a biomarker in clinical application like myocardial markers in the future. In conclusion, this review provides an overview of $\operatorname{lncRNAs}$ in autophagy regulation and new insights into the underlying mechanisms and may be able to provide new ideas for studying the possible role of lncRNAs on regulating the press of neurological diseases.

\section{Data Availability}

No data were used to support this study.

\section{Conflicts of Interest}

The authors declare that they have no conflicts of interest.

\section{Acknowledgments}

This work was supported by the National Nature Science Foundation of China (81671181), the Natural Science Foundation of Guangdong Province (2017A030310658), Guangdong Province Colleges and Universities Young Innovative Talents Project (2018KQNCX095), and Guangdong Province Universities and Colleges Pearl River Scholar Funding Scheme (2017).

\section{References}

[1] S. Oe, T. Kimura, and H. Yamada, "Regulatory non-coding RNAs in nervous system development and disease," Frontiers in Bioscience (Landmark edition), vol. 24, no. 7, pp. 12031240, 2019.

[2] J.-F. Wang, Z.-G. Mei, Y. Fu et al., "Puerarin protects rat brain against ischemia/reperfusion injury by suppressing autophagy via the AMPK-mTOR-ULK1 signaling pathway," Neural Regeneration Research, vol. 13, no. 6, pp. 989-998, 2018.

[3] I. Dikic and Z. Elazar, "Mechanism and medical implications of mammalian autophagy," Nature Reviews Molecular Cell Biology, vol. 19, no. 6, pp. 349-364, 2018.

[4] Z. Jiang, L. T. Watts, S. Huang et al., "The effects of methylene blue on autophagy and apoptosis in MRI-defined normal tissue, ischemic penumbra and ischemic core," PLoS One, vol. 10, no. 6, article e0131929, 2015.

[5] K. Hou, D. Xu, F. Li, S. Chen, and Y. Li, "The progress of neuronal autophagy in cerebral ischemia stroke: mechanisms, roles and research methods," Journal of the Neurological Sciences, vol. 400, pp. 72-82, 2019.

[6] M. Xilouri and L. Stefanis, "Autophagy in the central nervous system: implications for neurodegenerative disorders," CNS 
\& Neurological Disorders Drug Targets, vol. 9, no. 6, pp. 701719, 2010.

[7] O. Conway, H. A. Akpinar, V. V. Rogov, and V. Kirkin, "Selective autophagy receptors in neuronal health and disease," Journal of Molecular Biology, vol. 432, no. 8, pp. 2483-2509, 2020.

[8] E. Kesidou, R. Lagoudaki, O. Touloumi, K. N. Poulatsidou, and C. Simeonidou, "Autophagy and neurodegenerative disorders," Neural Regeneration Research, vol. 8, no. 24, pp. 2275-2283, 2013.

[9] A. Scrivo, M. Bourdenx, O. Pampliega, and A. M. Cuervo, "Selective autophagy as a potential therapeutic target for neurodegenerative disorders," The Lancet Neurology, vol. 17, no. 9, pp. 802-815, 2018.

[10] H. Choudhry, A. L. Harris, and A. McIntyre, "The tumour hypoxia induced non-coding transcriptome," Molecular Aspects of Medicine, vol. 47-48, pp. 35-53, 2016.

[11] K. Wang, C.-Y. Liu, L.-Y. Zhou et al., “APF lncRNA regulates autophagy and myocardial infarction by targeting miR-1883p," Nature Communications, vol. 6, no. 1, article 6779, 2015.

[12] L. H. Di Ge, S. Y. Huang, N. Peng et al., "Identification of a novel MTOR activator and discovery of a competing endogenous RNA regulating autophagy in vascular endothelial cells," Autophagy, vol. 10, no. 6, pp. 957-971, 2014.

[13] S. Y. Huang, W. Lu, N. M. Di Ge et al., "A new microRNA signal pathway regulated by long noncoding RNA TGFB2-OT1 in autophagy and inflammation of vascular endothelial cells," Autophagy, vol. 11, no. 12, pp. 2172-2183, 2015.

[14] T. Derrien, R. Johnson, G. Bussotti et al., "The GENCODE v7 catalog of human long noncoding RNAs: analysis of their gene structure, evolution, and expression," Genome Research, vol. 22, no. 9, pp. 1775-1789, 2012.

[15] A. Akella, S. Bhattarai, and A. Dharap, "Long noncoding RNAs in the pathophysiology of ischemic stroke," Neuromolecular Medicine, vol. 21, no. 4, pp. 474-483, 2019.

[16] M. Guttman, M. Garber, J. Z. Levin et al., "Ab initio reconstruction of cell type-specific transcriptomes in mouse reveals the conserved multi-exonic structure of lincRNAs," Nature Biotechnology, vol. 28, no. 5, pp. 503-510, 2010.

[17] S. Carpenter, D. Aiello, M. K. Atianand et al., "A long noncoding RNA mediates both activation and repression of immune response genes," Science (New York, N.Y.), vol. 341, no. 6147, pp. 789-792, 2013.

[18] K. Schaukowitch and T.-K. Kim, "Emerging epigenetic mechanisms of long non-coding RNAs," Neuroscience, vol. 264, pp. 25-38, 2014.

[19] X. Zhang, N. Wu, J. Wang, and Z. Li, "LncRNA MEG3 inhibits cell proliferation and induces apoptosis in laryngeal cancer via miR-23a/APAF-1 axis," Journal of Cellular and Molecular Medicine, vol. 23, no. 10, pp. 6708-6719, 2019.

[20] J. Guo, Z. Liu, and R. Gong, "Long noncoding RNA: an emerging player in diabetes and diabetic kidney disease," Clinical science (London, England: 1979), vol. 133, no. 12, pp. 1321-1339, 2019.

[21] J. P. Monteiro, M. Bennett, J. Rodor, A. Caudrillier, I. Ulitsky, and A. H. Baker, "Endothelial function and dysfunction in the cardiovascular system: the long non-coding road," Cardiovascular Research, vol. 115, no. 12, pp. 1692-1704, 2019.

[22] S. Barangi, A. W. Hayes, R. Reiter, and G. Karimi, "The therapeutic role of long non-coding RNAs in human diseases: a focus on the recent insights into autophagy," Pharmacological Research, vol. 142, pp. 22-29, 2019.

[23] K. C. Wang and H. Y. Chang, "Molecular mechanisms of long noncoding RNAs," Molecular Cell, vol. 43, no. 6, pp. 904-914, 2011.

[24] S. A. Bhat, S. M. Ahmad, P. T. Mumtaz et al., "Long noncoding RNAs: mechanism of action and functional utility," Non-coding RNA Research, vol. 1, no. 1, pp. 43-50, 2016.

[25] X. Han, F. Yang, H. Cao, and Z. Liang, "Malat1regulates serum response factor through miR-133 as a competing endogenous RNA in myogenesis," FASEB Journal, vol. 29, no. 7, pp. 3054-3064, 2015.

[26] Y. An, K. L. Furber, and S. Ji, "Pseudogenes regulate parental gene expression via ceRNA network," Journal of Cellular and Molecular Medicine, vol. 21, no. 1, pp. 185-192, 2017.

[27] B. Guennewig and A. A. Cooper, "The central role of noncoding RNA in the brain," International Review of Neurobiology, vol. 116, pp. 153-194, 2014.

[28] X. Li, Z. Wu, X. Fu, and W. Han, "IncRNAs: insights into their function and mechanics in underlying disorders," Mutation Research/Reviews in Mutation Research, vol. 762, pp. 1-21, 2014.

[29] A. Saxena and P. Carninci, "Long non-coding RNA modifies chromatin: epigenetic silencing by long non-coding RNAs," BioEssays: News and Reviews in Molecular, Cellular and Developmental Biology, vol. 33, no. 11, pp. 830-839, 2011.

[30] M.-C. Tsai, O. Manor, Y. Wan et al., "Long noncoding RNA as modular scaffold of histone modification complexes," Science (New York, N.Y.), vol. 329, no. 5992, pp. 689-693, 2010.

[31] M. Guttman, J. Donaghey, B. W. Carey et al., "lincRNAs act in the circuitry controlling pluripotency and differentiation," Nature, vol. 477, no. 7364, pp. 295-300, 2011.

[32] I. A. Qureshi and M. F. Mehler, "Long non-coding RNAs: novel targets for nervous system disease diagnosis and therapy," Neurotherapeutics, vol. 10, no. 4, pp. 632-646, 2013.

[33] M.-H. Bao, V. Szeto, B. B. Yang, S.-z. Zhu, H.-S. Sun, and Z.P. Feng, "Long non-coding RNAs in ischemic stroke," Cell Death \& Disease, vol. 9, no. 3, p. 281, 2018.

[34] F. Kopp and J. T. Mendell, "Functional classification and experimental dissection of long noncoding RNAs," Cell, vol. 172, no. 3, pp. 393-407, 2018.

[35] M. Hashemzaei, R. E. Heravi, R. Rezaee, A. Roohbakhsh, and G. Karimi, "Regulation of autophagy by some natural products as a potential therapeutic strategy for cardiovascular disorders," European Journal of Pharmacology, vol. 802, pp. 4451, 2017.

[36] W. P. Roos, A. D. Thomas, and B. Kaina, "DNA damage and the balance between survival and death in cancer biology," Nature Reviews Cancer, vol. 16, no. 1, pp. 20-33, 2016.

[37] J. Zhang, P. Wang, L. Wan, S. Xu, and D. Pang, "The emergence of noncoding RNAs as Heracles in autophagy," Autophagy, vol. 13, no. 6, pp. 1004-1024, 2017.

[38] R. Ng and K.-H. Chan, "Potential neuroprotective effects of adiponectin in Alzheimer's disease," International Journal of Molecular Sciences, vol. 18, no. 3, p. 592, 2017.

[39] J. Nah, J. Yuan, and Y.-K. Jung, "Autophagy in neurodegenerative diseases: from mechanism to therapeutic approach," Molecules and Cells, vol. 38, no. 5, pp. 381-389, 2015.

[40] Y. Zhao, Y. Zhang, L. Zhang, Y. Dong, H. Ji, and L. Shen, "The potential markers of circulating microRNAs and long 
non-coding RNAs in Alzheimer's disease," Aging and Disease, vol. 10, no. 6, pp. 1293-1301, 2019.

[41] S. Massone, I. Vassallo, G. Fiorino et al., "17A, a novel noncoding RNA, regulates GABA B alternative splicing and signaling in response to inflammatory stimuli and in Alzheimer disease," Neurobiology of Disease, vol. 41, no. 2, pp. 308-317, 2011.

[42] X. Wang, M. Zhang, and H. Liu, "LncRNA17A regulates autophagy and apoptosis of SH-SY5Y cell line as anin vitromodel for Alzheimer's disease," Bioscience, Biotechnology, and Biochemistry, vol. 83, no. 4, pp. 609-621, 2019.

[43] W. Nong, "Long non-coding RNA NEAT1/miR-193a-3p regulates LPS-induced apoptosis and inflammatory injury in WI-38 cells through TLR4/NF- $\kappa$ B signaling," American Journal of Translational Research, vol. 11, no. 9, pp. 5944-5955, 2019.

[44] S. Ke, Z. Yang, F. Yang, X. Wang, J. Tan, and B. Liao, "Long noncoding RNA NEAT1 aggravates $\mathrm{A} \beta$-induced neuronal damage by targeting miR-107 in Alzheimer's disease," Yonsei Medical Journal, vol. 60, no. 7, pp. 640-650, 2019.

[45] M.-Y. Zhao, G.-Q. Wang, N.-N. Wang, Q.-Y. Yu, R.-L. Liu, and W.-Q. Shi, "The long-non-coding RNA NEAT1 is a novel target for Alzheimer's disease progression via miR124/BACE1 axis," Neurological Research, vol. 41, no. 6, pp. 489-497, 2019.

[46] Z. Huang, J. Zhao, W. Wang, J. Zhou, and J. Zhang, "Depletion of LncRNA NEAT1 rescues mitochondrial dysfunction through NEDD4L-dependent PINK1 degradation in animal models of Alzheimer's disease," Frontiers in Cellular Neuroscience, vol. 14, p. 28, 2020.

[47] T. G. McWilliams and M. M. K. Muqit, "PINK1 and Parkin: emerging themes in mitochondrial homeostasis," Current Opinion in Cell Biology, vol. 45, pp. 83-91, 2017.

[48] Y. Lyu, L. Bai, and C. Qin, "Long noncoding RNAs in neurodevelopment and Parkinson's disease," Animal Models and Experimental Medicine, vol. 2, no. 4, pp. 239-251, 2019.

[49] M. Martinez-Vicente, "Autophagy in neurodegenerative diseases: from pathogenic dysfunction to therapeutic modulation," Seminars in Cell \& Developmental Biology, vol. 40, pp. 115-126, 2015.

[50] C. Klein and A. Westenberger, "Genetics of Parkinson's disease," Cold Spring Harbor Perspectives in Medicine, vol. 2, no. 1, article a008888, 2012.

[51] W. Yan, Z.-Y. Chen, J.-Q. Chen, and H.-M. Chen, "LncRNA NEAT1 promotes autophagy in MPTP-induced Parkinson's disease through stabilizing PINK1 protein," Biochemical and Biophysical Research Communications, vol. 496, no. 4, pp. 1019-1024, 2018.

[52] S.-P. Xie, F. Zhou, J. Li, and S.-j. Duan, "NEAT1 regulates $\mathrm{MPP}^{+}$-induced neuronal injury by targeting miR-124 in neuroblastoma cells," Neuroscience Letters, vol. 708, article 134340, 2019.

[53] S. Kawajiri, S. Saiki, S. Sato et al., "PINK1 is recruited to mitochondria with parkin and associates with LC3 in mitophagy," FEBS Letters, vol. 584, no. 6, pp. 1073-1079, 2010.

[54] T. F. J. Kraus, M. Haider, J. Spanner, M. Steinmaurer, V. Dietinger, and H. A. Kretzschmar, "Altered long noncoding RNA expression precedes the course of Parkinson's disease-a preliminary report," Molecular Neurobiology, vol. 54, no. 4, pp. 2869-2877, 2017.
[55] Y. Chen, Y.-j. Lian, Y.-q. Ma, C.-j. Wu, Y.-k. Zheng, and N.c. Xie, "LncRNA SNHG1 promotes $\alpha$-synuclein aggregation and toxicity by targeting miR-15b-5p to activate SIAH1 in human neuroblastoma SH-SY5Y cells," Neurotoxicology, vol. 68, pp. 212-221, 2018.

[56] C. Qian, Y. Ye, H. Mao et al., "Downregulated lncRNASNHG1 enhances autophagy and prevents cell death through the miR-221/222 /p27/mTOR pathway in Parkinson's disease," Experimental Cell Research, vol. 384, no. 1, p. 111614, 2019.

[57] S. Wang, X. Zhang, Y. Guo, H. Rong, and T. Liu, "The long noncoding RNA HOTAIR promotes Parkinson's disease by upregulating LRRK2 expression," Oncotarget, vol. 8, no. 15, pp. 24449-24456, 2017.

[58] E. D. Plowey, S. J. Cherra, Y.-J. Liu, and C. T. Chu, "Role of autophagy in G2019S-LRRK2-associated neurite shortening in differentiated SH-SY5Y cells," Journal of Neurochemistry, vol. 105, no. 3, pp. 1048-1056, 2008.

[59] Q. Lin, S. Hou, Y. Dai, N. Jiang, and Y. Lin, "LncRNA HOTAIR targets miR-126-5p to promote the progression of Parkinson's disease through RAB3IP," Biological Chemistry, vol. 400, no. 9, pp. 1217-1228, 2019.

[60] Z. Deng, P. Sheehan, S. Chen, and Z. Yue, "Is amyotrophic lateral sclerosis/frontotemporal dementia an autophagy disease?," Molecular Neurodegeneration, vol. 12, no. 1, p. 90, 2017.

[61] "Expression of Concern:Long noncoding RNA HAGLROS regulates apoptosis and autophagy in Parkinson's disease via regulating miR-100/ATG10 axis and PI3K/Akt/mTOR pathway activation," Artificial Cells, Nano Medicine, and Biotechnology, vol. 48, no. 1, p. 708, 2020.

[62] W. Wang, B. Jiang, H. Sun et al., "Prevalence, incidence, and mortality of stroke in China," Circulation, vol. 135, no. 8, pp. 759-771, 2017.

[63] S. Wu, B. Wu, M. Liu et al., "Stroke in China: advances and challenges in epidemiology, prevention, and management," The Lancet Neurology, vol. 18, no. 4, pp. 394-405, 2019.

[64] M. Yemisci, S. Caban, Y. Gursoy-Ozdemir et al., "Systemically administered brain-targeted nanoparticles transport peptides across the blood-brain barrier and provide neuroprotection," Journal of Cerebral Blood Flow and Metabolism: Official Journal of the International Society of Cerebral Blood Flow and Metabolism, vol. 35, no. 3, pp. 469-475, 2015.

[65] S. E. Khoshnam, W. Winlow, M. Farzaneh, Y. Farbood, and H. F. Moghaddam, "Pathogenic mechanisms following ischemic stroke," Neurological Sciences, vol. 38, no. 7, pp. 11671186, 2017.

[66] Z. Yang, L. Zhong, S. Zhong, R. Xian, and B. Yuan, "Hypoxia induces microglia autophagy and neural inflammation injury in focal cerebral ischemia model," Experimental and Molecular Pathology, vol. 98, no. 2, pp. 219-224, 2015.

[67] S. Carloni, S. Girelli, C. Scopa, G. Buonocore, M. Longini, and W. Balduini, "Activation of autophagy and Akt/CREB signaling play an equivalent role in the neuroprotective effect of rapamycin in neonatal hypoxia-ischemia," Autophagy, vol. 6, no. 3, pp. 366-377, 2014.

[68] C. Wu, X. Yan, Y. Liao et al., "Increased perihematomal neuron autophagy and plasma thrombin-antithrombin levels in patients with intracerebral hemorrhage: an observational study," Medicine, vol. 98, no. 39, article e17130, 2019. 
[69] S. L. Mehta, T. Kim, and R. Vemuganti, "Long noncoding RNA FosDT promotes ischemic brain injury by interacting with REST-associated chromatin-modifying proteins," The Journal of Neuroscience: The Official Journal of the Society for Neuroscience, vol. 35, no. 50, pp. 16443-16449, 2015.

[70] H.-C. Chi, C.-Y. Tsai, M.-M. Tsai, C.-T. Yeh, and K.-H. Lin, "Molecular functions and clinical impact of thyroid hormone-triggered autophagy in liver-related diseases," Journal of Biomedical Science, vol. 26, no. 1, p. 24, 2019.

[71] J. Wang, B. Cao, D. Han, M. Sun, and J. Feng, "Long noncoding RNA H19 induces cerebral ischemia reperfusion injury via activation of autophagy," Aging and Disease, vol. 8, no. 1, pp. 71-84, 2017.

[72] J. Zhang, L. Yuan, X. Zhang et al., “Altered long non-coding RNA transcriptomic profiles in brain microvascular endothelium after cerebral ischemia," Experimental Neurology, vol. 277, pp. 162-170, 2016.

[73] D. Guo, J. Ma, L. Yan et al., "Down-regulation of Lncrna MALAT1 attenuates neuronal cell death through suppressing Beclin1-dependent autophagy by regulating Mir-30a in cerebral ischemic stroke," Cellular Physiology and Biochemistry, vol. 43, no. 1, pp. 182-194, 2017.

[74] Z. Li, J. Li, and N. Tang, "Long noncoding RNA Malat1 is a potent autophagy inducer protecting brain microvascular endothelial cells against oxygen-glucose deprivation/reoxygenation-induced injury by sponging miR-26b and upregulating ULK2 expression," Neuroscience, vol. 354, pp. 1-10, 2017.

[75] S. Wang, X. Han, Z. Mao, Y. Xin, S. Maharjan, and B. Zhang, "MALAT1 lncRNA induces autophagy and protects brain microvascular endothelial cells against oxygen-glucose deprivation by binding to miR-200c-3p and upregulating SIRT1 expression," Neuroscience, vol. 397, pp. 116-126, 2019.

[76] X. Yao, R. Yao, F. Huang, and J. Yi, "LncRNA SNHG12 as a potent autophagy inducer exerts neuroprotective effects against cerebral ischemia/reperfusion injury," Biochemical and Biophysical Research Communications, vol. 514, no. 2, pp. 490-496, 2019.

[77] M. Vausort, D. R. Wagner, and Y. Devaux, "Long noncoding RNAs in patients with acute myocardial infarction," Circulation Research, vol. 115, no. 7, pp. 668-677, 2014.

[78] S. Yu, M. Yu, X. He, L. Wen, Z. Bu, and J. Feng, "KCNQ1OT1 promotes autophagy by regulating miR-200a/FOXO3/ATG7 pathway in cerebral ischemic stroke," Aging Cell, vol. 18, no. 3, article e12940, 2019.

[79] F. Meng, Y. You, Z. Liu, J. Liu, H. Ding, and R. Xu, "Neuronal calcium signaling pathways are associated with the development of epilepsy," Molecular Medicine Reports, vol. 11, no. 1, pp. 196-202, 2015.

[80] Y. Huang, X. Liu, Y. Liao et al., "MiR-181a influences the cognitive function of epileptic rats induced by pentylenetetrazol," International Journal of Clinical and Experimental Pathology, vol. 8, no. 10, pp. 12861-12868, 2015.

[81] Q. Wu and X. Yi, "Down-regulation of long noncoding RNA MALAT1 protects hippocampal neurons against excessive autophagy and apoptosis via the PI3K/Akt signaling pathway in rats with epilepsy," Journal of Molecular Neuroscience: MN, vol. 65, no. 2, pp. 234-245, 2018.

[82] X. Song, N. Zhang, P. Han et al., "Circular RNA profile in gliomas revealed by identification tool UROBORUS," Nucleic Acids Research, vol. 44, no. 9, p. e87, 2016.
[83] R. K. Jain, E. di Tomaso, D. G. Duda, J. S. Loeffler, A. G. Sorensen, and T. T. Batchelor, "Angiogenesis in brain tumours," Nature Reviews Neuroscience, vol. 8, no. 8, pp. 610-622, 2007.

[84] L. Kelland, "The resurgence of platinum-based cancer chemotherapy," Nature Reviews Cancer, vol. 7, no. 8, pp. 573584, 2007.

[85] P. Li, J. He, Z. Yang et al., "ZNNT1long noncoding RNA induces autophagy to inhibit tumorigenesis of uveal melanoma by regulating key autophagy gene expression," Autophagy, vol. 16, no. 7, pp. 1186-1199, 2020.

[86] N. Zhang, Z. Li, F. Bai, and S. Zhang, "PAX5-induced upregulation of IDH1-AS1 promotes tumor growth in prostate cancer by regulating ATG5-mediated autophagy," Cell Death \& Disease, vol. 10, no. 10, p. 734, 2019.

[87] F. Zhang, T. Yan, W. Guo et al., "Novel oncogene COPS3 interacts with Beclin1 and Raf-1 to regulate metastasis of osteosarcoma through autophagy," Journal of Experimental \& Clinical Cancer Research, vol. 37, no. 1, p. 135, 2018.

[88] H. Zhao, X. Wang, X. Feng et al., "Long non-coding RNA MEG3 regulates proliferation, apoptosis, and autophagy and is associated with prognosis in glioma," Journal of NeuroOncology, vol. 140, no. 2, pp. 281-288, 2018.

[89] N. Qin, G.-F. Tong, L.-W. Sun, and X.-L. Xu, "Long noncoding RNA MEG3 suppresses glioma cell proliferation, migration, and invasion by acting as a competing endogenous RNA of miR-19a," Oncology Research, vol. 25, no. 9, pp. 1471-1478, 2017.

[90] L. Jiang, C. Wang, F. Lei et al., "miR-93 promotes cell proliferation in gliomas through activation of PI3K/Akt signaling pathway," Oncotarget, vol. 6, no. 10, pp. 8286-8299, 2015.

[91] H. Shi, Y. Ji, D. Zhang, Y. Liu, and P. Fang, "MicroRNA3666-induced suppression of SIRT7 inhibits the growth of non-small cell lung cancer cells," Oncology Reports, vol. 36, no. 5, pp. 3051-3057, 2016.

[92] D.-. H. Xu, G.-. N. Chi, C.-. H. Zhao, and D.-. Y. Li, "Long noncoding RNA MEG3 inhibits proliferation and migration but induces autophagy by regulation of Sirt7 and $\mathrm{PI} 3 \mathrm{~K} / \mathrm{AKT} / \mathrm{mTOR}$ pathway in glioma cells," Journal of Cellular Biochemistry, vol. 120, no. 5, pp. 7516-7526, 2018.

[93] B. Ma, Z. Gao, J. Lou et al., "Long non-coding RNA MEG3 contributes to cisplatin-induced apoptosis via inhibition of autophagy in human glioma cells," Molecular Medicine Reports, vol. 16, no. 3, pp. 2946-2952, 2017.

[94] Y. Ma, P. Wang, Y. Xue et al., "PVT1 affects growth of glioma microvascular endothelial cells by negatively regulating $\mathrm{miR}$ 186," Tumour Biology, vol. 39, no. 3, 2017.

[95] K.-x. Ma, H.-j. Wang, X.-r. Li et al., "Long noncoding RNA MALAT1 associates with the malignant status and poor prognosis in glioma," Tumour Biology, vol. 36, no. 5, pp. 3355-3359, 2015.

[96] Z. Fu, W. Luo, J. Wang et al., "Malat1 activates autophagy and promotes cell proliferation by sponging miR-101 and upregulating STMN1, RAB5A and ATG4D expression in glioma," Biochemical and Biophysical Research Communications, vol. 492, no. 3, pp. 480-486, 2017.

[97] Y. Lu, S. Dong, B. Hao et al., "Vacuolin-1 potently and reversibly inhibits autophagosome-lysosome fusion by activating RAB5A," Autophagy, vol. 10, no. 11, pp. 1895-1905, 2014.

[98] S. Abreu, F. Kriegenburg, R. Gómez-Sánchez et al., "Conserved Atg8 recognition sites mediate Atg4 association with 
autophagosomal membranes and Atg8 deconjugation," EMBO Reports, vol. 18, no. 5, pp. 765-780, 2017.

[99] H. Mo, J. He, Z. Yuan et al., "PLK1 contributes to autophagy by regulating MYC stabilization in osteosarcoma cells," OncoTargets and Therapy, vol. 12, pp. 7527-7536, 2019.

[100] R. Ma, B.-W. Zhang, Z.-B. Zhang, and Q.-J. Deng, "LncRNA MALAT1 knockdown inhibits cell migration and invasion by suppressing autophagy through miR-384/GOLM1 axis in glioma," European Review for Medical and Pharmacological Sciences, vol. 24, no. 5, pp. 2601-2615, 2020.

[101] R. Xu, J. Ji, X. Zhang et al., "PDGFA/PDGFR $\alpha$-regulated GOLM1 promotes human glioma progression through activation of AKT," Journal of Experimental \& Clinical Cancer Research, vol. 36, no. 1, p. 193, 2017.

[102] J. Shen, T. R. Hodges, R. Song et al., "Serum HOTAIR and GAS5 levels as predictors of survival in patients with glioblastoma," Molecular Carcinogenesis, vol. 57, no. 1, pp. 137-141, 2018.

[103] J.-. F. Huo and X.-. B. Chen, "Long noncoding RNA growth arrest-specific 5 facilitates glioma cell sensitivity to cisplatin by suppressing excessive autophagy in an mTOR-dependent manner," Journal of Cellular Biochemistry, vol. 120, no. 4, pp. 6127-6136, 2019.

[104] D. Scoles and S. Pulst, "Oligonucleotide therapeutics in neurodegenerative diseases," RNA Biology, vol. 15, no. 6, pp. 707-714, 2018.

[105] E. Doxakis, “Therapeutic Antisense Oligonucleotides for Movement Disorders," Medicinal Research Reviews, 2020.

[106] D. de Bruin, N. Bossert, A. Aartsma-Rus, and D. Bouwmeester, "Measuring DNA hybridization using fluorescent DNA-stabilized silver clusters to investigate mismatch effects on therapeutic oligonucleotides," Journal of Nanobiotechnology, vol. 16, no. 1, p. 37, 2018.

[107] D. Dash and T. A. Mestre, "Therapeutic update on Huntington's disease: symptomatic treatments and emerging diseasemodifying therapies," Neurotherapeutics, pp. 1-15, 2020. 